\title{
A Mechanism of Turbulent Transfer in the Atmospheric Surface Layer
}

\author{
By S. Ito \\ Japan Meteorological Agency \\ (manuscript received 10 march 1969, in revised form 14 October 1969)
}

\begin{abstract}
Micro-meteorological data are analysed to determine the flux-gradient relationships for the tarnsfer of momentum, sensible heat and water vapor in the atmospheric surface layer.

The results obtained agree well with the universal relationships under the condition of $(z / L)$ varying from 0 to -1 for the unstable and from 0 to 0.25 for the stable. The universal relationships imply a relationship between eddy diffusivity and the stability parameter $z / L$. The derivation shows that the gradient Richardson number $R i$ is not equal to the $z / L$. Empirical evidence for the validity is obtained.

A turbulent-scale, which is derived in this report, is related to the eddy diffusivities. The results show that the eddy diffusivities for momentum, sensible heat and water vapor are expressed respectively by

$$
K_{M}=\varepsilon^{1 / 3} L u^{4 / 3} \quad K_{H}=\varepsilon^{1 / 3} L_{u^{1 / 3}} \cdot L_{\theta} \quad K_{w}=\varepsilon^{1 / 3} L_{u^{1 / 3}} \cdot L_{w}
$$

Here, $L_{i}$ indicates the turbulent-scale in the vertical direction of wind, temperature and water vapor respectively with a subscript of $u, \theta$ and $w . \varepsilon$ is the dissipation rate of turbulent energy.
\end{abstract}

\section{Introduction}

The similarity theory (Monin and Obukhov 1954) for the turbulent regime in a thermally stratified surface layer of the atmosphere is now well appreciated. It has provided a fundamental framework discussed by many workers with the observational data (Taylor 1960, Takeuchi 1961, Pandolfo 1966, and Businger 1966) in order to determine the universal characteristics of turbulent structure in the atmospheric surface layer.

The main difficulty in determining of the turbulent characteristics is related to the incomplete conditions of the systme of equations describing the turbulent condition in the atomspheric surface layer.

In spite of the incomplete set of equations, the definite progress in recent work has been made in the description of diabtic wind profiles with the assumptions respecting to the eddy viscosity in order to make the complete set of equations (Kazanski and Monin 1956, and Yamamoto 1959).

The underlying concept of the present approach is to establish the flux-gradient relationships with observed facts and to discuss the mechanism of turbulent transfer making use of recent results obtained by observations of profiles of wind, temperature and water vapor.

An expedition nicknamed the Futtu project was carried out in August 1966 at Futtu sea-coast, which locates at the distance some $40 \mathrm{~km}$ south of Tokyo. In this area, the surface is relatively flat covered with sand. The meteorological observations were made with towers $8 \mathrm{~m}$ high located at about $20 \mathrm{~m}$ inland from the shore-line.

The data used in this paper were chosen due to the wind direction. Those obtained for the wind direction along the coast line were exclusively made use of in order to avoid the unnecessary complications which might be caused by sea breeze and local protuberance due to the pine-trees composing wind breaks. All runs were made for 10 min durations, and the strict attention was paid to theoretical requirements of the steady condition. Wind measurements were made at eight heights of $0.25,0.50,0.75,1,2,3,4$ and $6 \mathrm{~m}$ with the three-cup anemometers of Rikokentype. The profiles of temperature were obtained using the thermistor-registance thermometers at the heights mentioned above. The water vapor profiles were also measured by the psychrometric system with wet-thermistors.

Almost all runs were carried out mainly during 
the day-time, but only a few data were obtained at night, too. The results obtained in the Great Plains Turbulence Field Programe made in U.S.A. (Lettau and Davidson 1963), that was indicated as G. Plain Project in this report, were also used in this paper in order to cover the shortage of data in this Futtu Project especially for the data in the night-time.

In letter half part of this paper, the discussions are extended to collect further evidence to confirm the relation of the shape function against $z / L$. After that, one would devote to seek the basic character for the turbulent transfer. Existing evidence indicates that the relative magnitude of $K_{M}$ and $K_{H}$ has not yet been answered satisfactorily. The ratio of the eddy diffusivity is unity in neutral air but increases with decreasing $z / L$ (Swinbank 1955, Lettau and Davidson 1957, Ellison 1957, Record and Cramer 1966 etc.). Ellison (1957) has shown that the turbulent transport of any neutral density substance takes place in exactly the same manner as the turbulent transport of sensible heat. According to Dyer (1967), this means that $K_{H}=K_{w}$ but one may have a remark that density of water vapor is smaller than that of air. However, Pasquill (1949, see Crawford 1965) has reported that to show $K_{H}$ approaching $2 K_{w}$ under unstable condition. On the other hand, reciprocal of the Prandtl number is, in general, smaller than that of the Schmidt number in molecular transfer. This fact is to be noticed.

To solve this conflict, one would devote to seek out the transfer process with the reasonable discussion.

\section{Data analysis}

Following Monin and Obukhov (1954), one may introduce non-dimensional wind shear in a form of

$$
S=k z / v_{*} \cdot d v / d z
$$

By analogy, one may also define non-dimensional temperature gradient by

$$
R=z / T_{*} \cdot d \theta / d z
$$

A non-dimensional water vapor gradient is, here, introduced, which is given by

$$
P=k z v_{*} /-E / \rho_{0} \cdot d q / d z
$$

There should exist the universal relations between the non-dimensional gradients and $z / L$, where $L$ is defined by $L=-v_{*}^{3} /\left(k \cdot g / \theta_{0} \cdot H / c_{p} \rho_{0}\right)$. Here,

$$
\begin{aligned}
z & =\text { height above the surface } \\
v & =\text { wind speed } \\
v_{*} & =\text { friction velocity } \\
k & =\text { Von Karman constant } \\
\theta & =\text { temperature } \\
\theta_{0} & =\text { representative temperature } \\
g & =\text { gravitational acceleration } \\
T_{*} & =\left(-H / k \cdot v_{*} \cdot c_{p} \rho_{0}\right), \text { friction temperature } \\
H & =\text { sensible heat flux } \\
c_{p} & =\text { specific heat of air } \\
\rho_{0} & =\text { air density } \\
E & =\text { water vapor flux } \\
q & =\text { mixing ratio }
\end{aligned}
$$

By using the eddy viscosity hypothesis and neglecting molecular transfer terms, the vertical fluxes of momentum, sensible heat and water vapor can be represented respectively by the product of the eddy viscosity and the vertical gradient as the following equation:

$$
\begin{gathered}
v_{*}^{2}=K_{M} \cdot d v / d z \\
k v_{*} T_{*}=K_{H} \cdot d \theta / d z \\
-E / \rho_{0}=K_{w} \cdot d q / d z
\end{gathered}
$$

Here,

$K_{M}=$ diffusivity for momentum

$K_{H}=$ diffusivity for sensible heat

$K_{w}=$ diffusivity for water vapor

Then, the definitions of eddy diffusivities can be rewritten making use of the non-dimensional gradients by

$$
\begin{aligned}
& K_{M} /\left(k z v_{*}\right)=1 / S \\
& K_{H} /\left(k z v_{*}\right)=1 / R \\
& K_{w} /\left(k z v_{*}\right)=1 / P
\end{aligned}
$$

Thus, definite progress is expected from seeking out the universal formulation on the non-dimensional gradient form.

In order to avoid an error of a finite difference, one introduces favorable scheme (Margenau 1943) for the calculation of a gradient with a formula given by

$$
\begin{aligned}
(d U / d z)_{z=z_{K}}= & 1 / 12 h\left[U_{K+3}-6 U_{K+2}\right. \\
& \left.+18 U_{K+1}-10 U_{K}-3 U_{K-1}\right]
\end{aligned}
$$

after smoothing out the small ripples in a profile. Here, $h$ is taken $0.5 \mathrm{~m}$, and $U=v, \theta$ or $q$. 


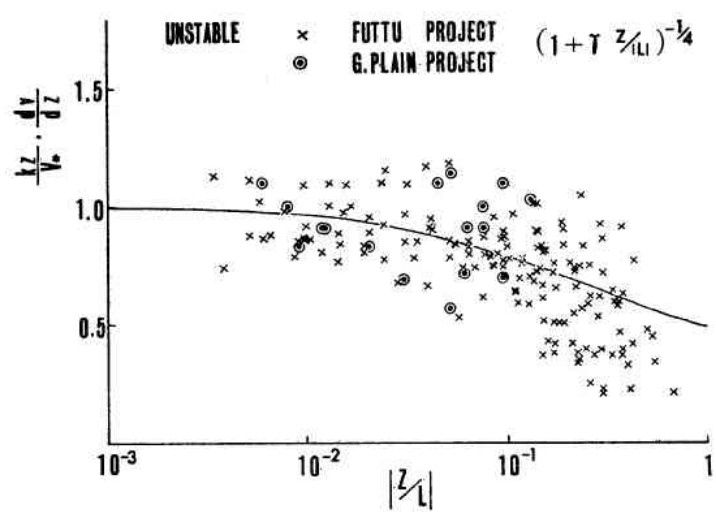

Fig. 1a Values of $S$ plotted against $|z / L|$ in unstable air. The full line represents an assesment of $S$ via $|z / L|$ from the shape function of eq. (3-1a).

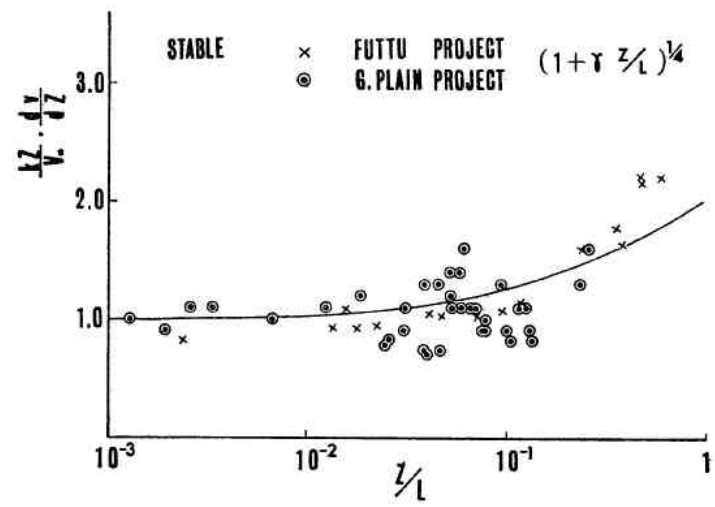

Fig. 1b Values of $S$ plotted against $z / L$ in stable air. The full line represents an assesment of $S$ via $z / L$ from the shape function of eq. (3-1b).

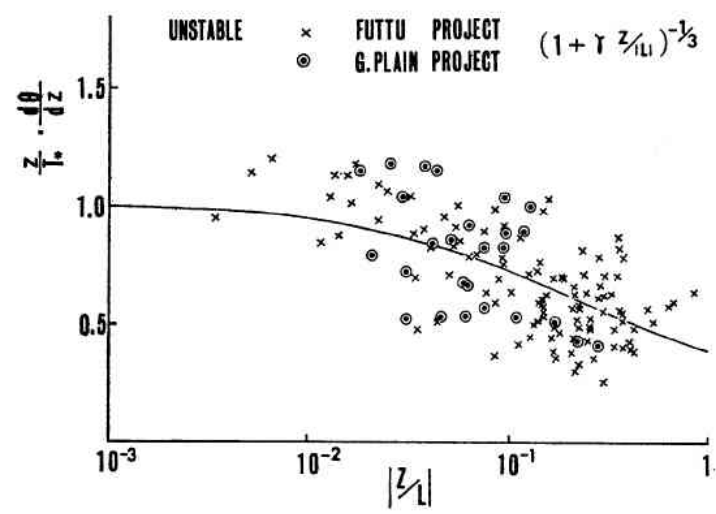

Fig. 2a Values of $R$ plotted against $|z / L|$ in unstable air. The full line represents an assesment of $R$ via $z / L$ from the shape function of eq. (3-2a).

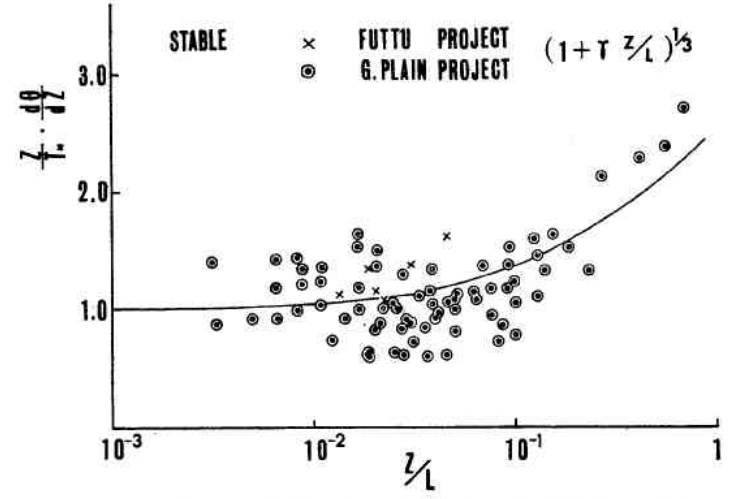

Fig. 2b Values of $R$ plotted against $|z / L|$ in stable air. The full line represents an assesment of $R$ via $|z / L|$ from the shape function of eq. (3-2b).

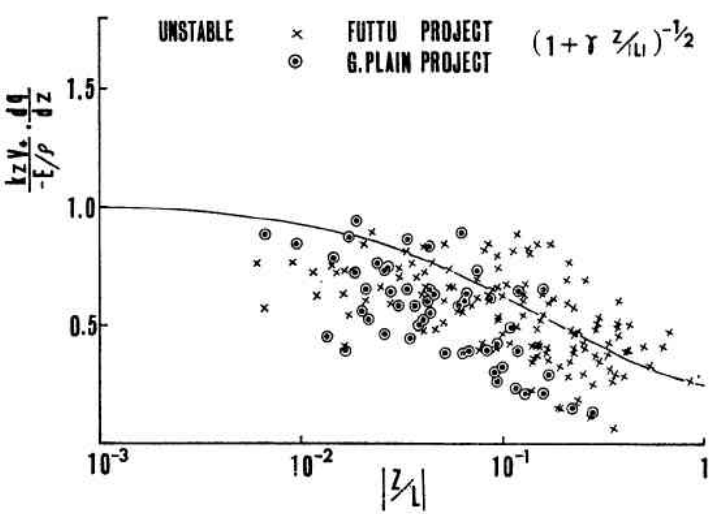

Fig. 3a Values of $P$ plotted against $|z / L|$ in unstable air. The full line represents an assesment of $P$ via $|z / L|$ from the shape function of eq. (3-3a).

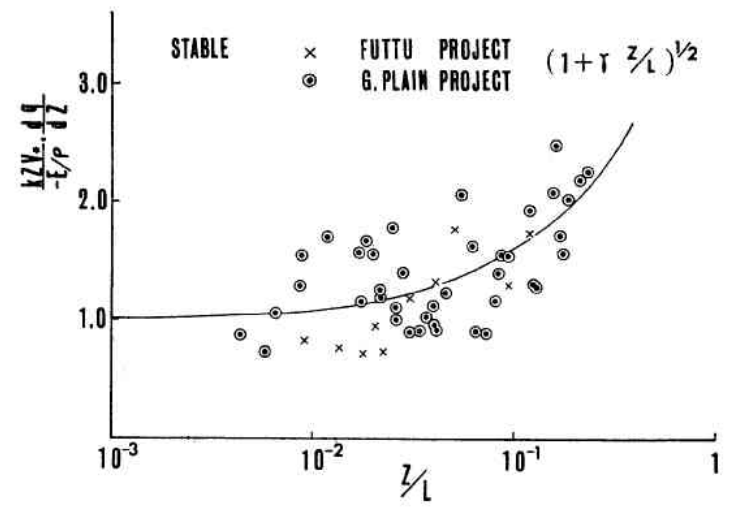

Fig. 3b Values of $P$ plotted against $z / L$ in stable air. The full line represents an assesment of $P$ via $z / L$ from the shape function of eq. (3-3b). 
Now, $v_{*}, T_{*}$ and $E$ were obtained, in most cases, from wind, temperature and mixing ratio at a low level with aid of a logarithmic profile, which holds at near the surface.

Values of $S, R$ and $P$ calculated according to the scheme mentioned above are plotted against $z / L$ in Figs. 1,2 , and 3 . It should be noted that the relationships established between the non-dimensional gradient and $z / L$ are applicable to the ranges $0<|z / L|<1$ for unstable condition and $0<|z / L| \ll 1$ for stable condition.

\section{The comparisons of observations with semi- empirical formula}

One may estimate the non-dimensional wind shear from the semi-empirical formulation (Businger 1966, and Yamamoto 1959) as

$$
S=(1-\gamma z / L)^{-1 / 4}
$$

for unstable condition, and

$$
S=(1+\gamma z / L)^{1 / 4}
$$

for stable condition.

One will, hereafter, call eq. (3-1) as a shape function of wind. The full line shows obviously good agreement between the observations and the shape function as can be seen in Fig. 1 with somewhat scatter.

Following Taylor's expansion, eq. (3-1b) can also be written as $S=(1+r / 4 \cdot z / L \cdots \cdots)$, which is well known formula with few evidenc under the stable condition (McVehil 1964). It is, however, to be noted that eq. (3-1b) agrees better than the form by Taylor's expansion. This is only reason to support ecl. (3-1b). On the other hand, they must be kept in mind that many of generalization are of doubtful validity with a light wind at night. This should partly be a result from neglecting radiant flux.

In general, $\gamma$ has been assumed an empirical constant which yields the best fit with observations. Good agreement of eq. (3-1a) with detailed profile measurement have been found by Paulson (1967) using $\gamma=16$. On the one hand, the constant $r$ has been given the physical meaning of the transfer coefficient though the discussion has been related to less empirical theory (Businger 1961). So far, much experimental evidence for the constant has been collected (cf. Lumley and Panofsky 1954). The value of 16 seems quite reasonable by the present data and progressive treatment mentioned above. Thus one may assume here tentatively that $\gamma$ should keep a value of 16 for a shape function of temperature and of water vapor. Then, one can focus only on the discussion of a power for each shape function.

The formulation for the shape function of temperature would be expected from the similarity theory to be same as eq. (3-1). The only different situation, however, could be estimated from the dimensional consideration, which has been discussed by Priestley (1954) and independently by Monin and Obukhov (1954). That is to say, the lapse rate of temperature is a function of $z, g / \theta_{0}$ and $-H / c_{p} \rho_{0}$ in the ranges $|z / L|>0.03$ of the unstable surface layer. The dimensional analysis shows that the lapse rate is proportional to the $-4 / 3$ power of height. When the power is taken into account for the shape function of temperature, one should express it as follows:

$$
R=(1-\gamma z / L)^{-1 / 3}
$$

for unstable condition, and

$$
R=(1+\gamma z / L)^{1 / 3}
$$

for stable condition.

The formulae fit for temperature-observations both in the unstable and the stable surface layer with somewhat scatter as shown by the full lines in Fig. 2.

Referring to the findings by Dyer (1967), who shed some light on the transfer mechanism for sensible heat and water vapor, the semi-empirical function of the temperature profile would be applicable to the shape function of water vapor. There is, however, an indication that the transfer process of sensible heat and water vapor might be not identical each other with the data obtained in the Futtu Project. Thus one may propose that the plausible power for the shape function of water vapor is proportional to the $-1 / 2$ power with height in the unstable condition. The facts that eq. (3-3) was observed to hold, are shown in Fig. 3 by a full line, and they are written by

$$
P=(1-\gamma z / L)^{-1 / 2}
$$

for unstable condition, and

$$
P=(1+\gamma z / L)^{1 / 2}
$$

for stable condition. 


\section{The non-dimensional flux}

The foregoing analysis indicates that the transfer mechanism for momentum, sensible heat and water vapor is not identical with each other in the thermaly stratified atmospheric flow.

To help resolution of the tentative results as mentioned above, it would be good approach to define the non-dimensional momentum flux $\stackrel{*}{U}$, sensible heat flux $\stackrel{*}{H}$ and evaporative flux $\stackrel{*}{E}$ respectively and then to investigate their variations with change of thermal stability.

$$
\begin{aligned}
U & =v_{*}^{2} /\left(g / \theta_{0}\right)^{1 / 2} \cdot|d v / d z| \cdot|d \theta / d z|^{1 / 2} \cdot z^{2} \\
& =k^{2} /|z / L|^{1 / 2} \cdot S \cdot R^{1 / 2}
\end{aligned}
$$

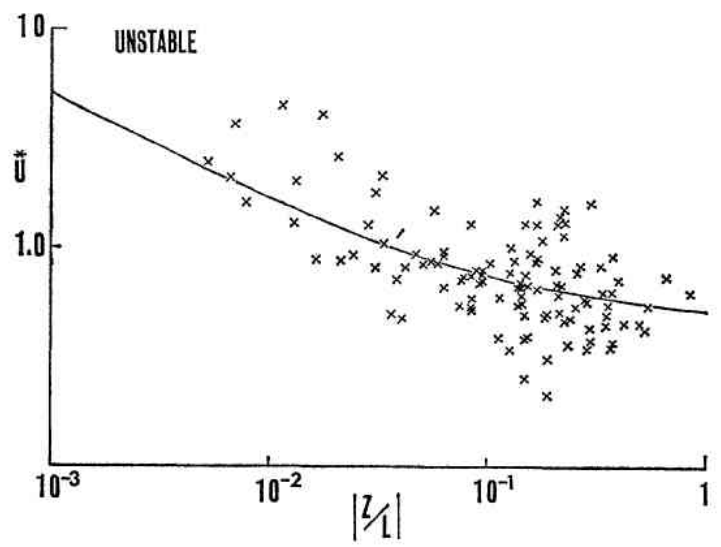

Fig. $4 \mathrm{a}$ Non-dimensional momentum flux as a function of $|z / L|$. Full line shows the relation calculated from the two shape functions in unstable air.

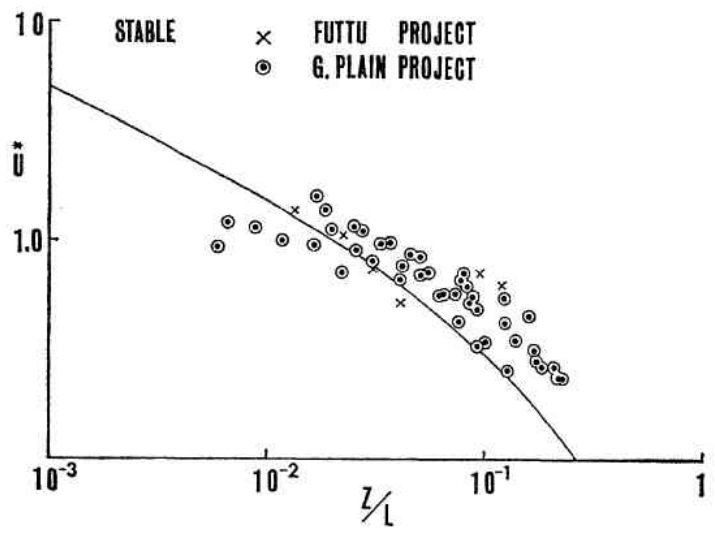

Fig. 4b Non-dimensional momentum flux as a function of $z / L$. Full line shows the relation calculated from the two shape functions in stable air.

$$
\begin{aligned}
\stackrel{*}{H} & =|H| / \rho_{0} c p\left(g / \theta_{0}\right)^{1 / 3} \cdot|d \theta / d z|^{3 / 2} \cdot z^{2} \\
& =k^{2} /|z / L|^{1 / 2} \cdot R^{3 / 2} \\
\stackrel{*}{E} & =|E| / \rho_{0}\left(g / \theta_{0}\right)^{1 / 2} \cdot|d q / d z| \cdot|d \theta / d z|^{1 / 2} \cdot z^{2} \\
& =k^{2} /|z / L|^{1 / 2} \cdot P \cdot R^{1 / 2}
\end{aligned}
$$

Data for ${ }^{*}$ are plotted against $z / L$ in Fig. 4. The full lines show that the shape functions are in good agreement with observed ones in Fig. 4. The observations of $\stackrel{*}{U}$ do not indicate a fairly sharp transition to free convection at $z / L=0.02$ to 0.03 . It is to be noted that the data give roughly estimation as $\stackrel{*}{\vec{U}}=0.8$ in the range of free convection.

Examining $\stackrel{*}{H}$ as shown in Fig. 5, one can

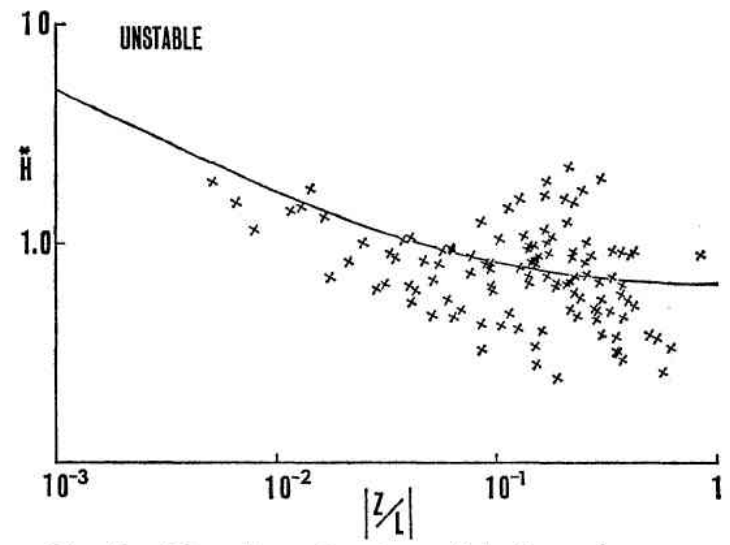

Fig. 5a Non-dimensional sensible heat flux as a function of $|z / L|$. Full line shows the relation calculated from the shape function in unstable air.

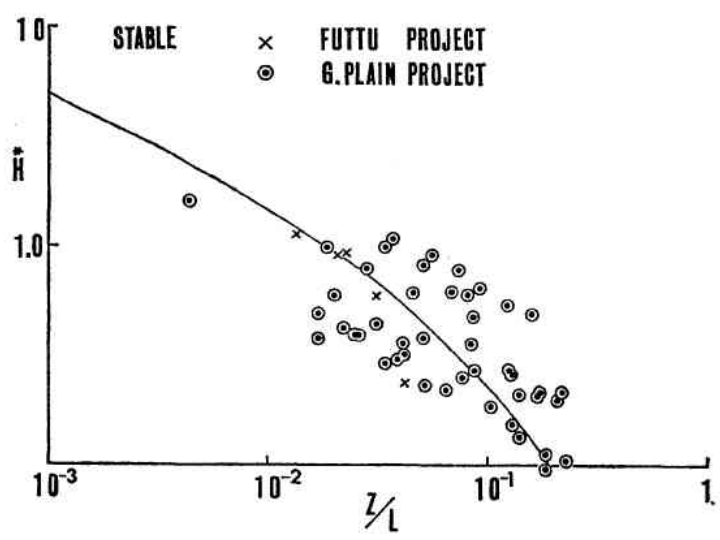

Fig. 5b Non-dimensional sensible heat flux as a function of $z / L$. Full line shows the relation calculated from the shape function in stable air. 


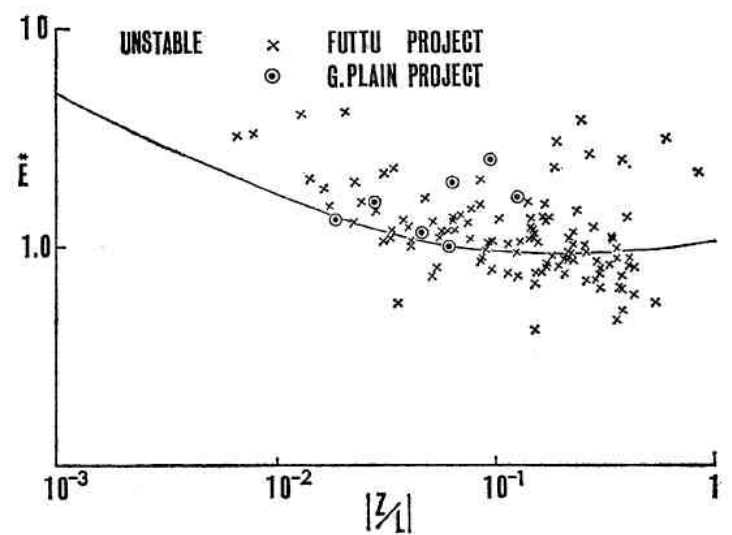

Fig. 6a Non-dimensional evaporative flux as a function of $|z / L|$. Full line shows the relation calculated from the two shape functions in unstable air.

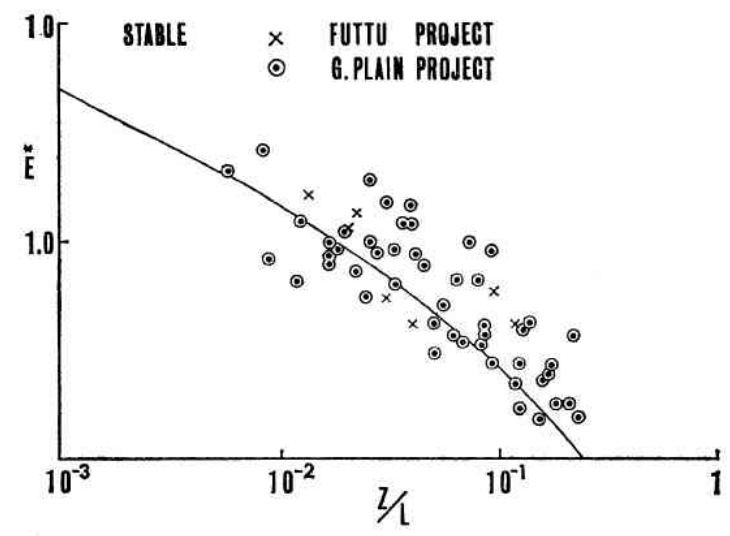

Fig. $6 \mathrm{~b}$ Non-dimensional evaporative flux as a function of $z / L$. Full line shows the relation calculated from the two shape functions in stable air.

realize that the shape function of temperature is again well consisted with the observations. Thus one can reveal that the shape function of temperature should become a meaningful formula.

The data of $\stackrel{*}{E}$ indicate certainly very smooth transition to the range of free convection as shown in Fig. 6-a in unstable air. It is, however, important to be emphasized that the shape function leads to somewhat larger values of $E^{*}$ than that of $\stackrel{*}{H}$ in the range of free convection by the combination of $P$ and $R$. This means that the power of shape function for sensible heat and water vapor might differ from each other. Comparing the present analysis with other suggestions that are 0.853 by Priestly (1960), 0.9 0.85 by Webb (1962), 0.83 by Dyer (1965) and
1.15 by Dyer (1967) for $\stackrel{*}{H}$, as well as 1.4 by Crawford (1967) for $\stackrel{*}{E}$, the powers of each shape function are in reasonable agreement with the results obtained.

It is finally to be emphasized that the turbulent transfer in stable condition decreases rapidly with increasing $z / L$, and the appreciable fluxes come to stop at about $z / L=0.25$. This is an indication that turbulence is very infirm with stable stratification from the value of about $R i=+0.2$ in the atmospheric surface layer (Lumley and Panofsky 1964, p. 73).

\section{Discussion}

In foregoing discussion, the starting point was in the formulation of the shape function for wind in unstable condition. Then, the other shape functions were compared carefully with the shape function of wind to find out some difference of that. Now, it would be needed to confirm that the wind profile are expressed with integral form of eq. (3-1a). This is done, here, via integral, which is written by

$$
\begin{aligned}
D^{-1} \cdot S_{1}= & \left.D^{-1} \cdot[1+\gamma|z / L|)^{-1 / 4} /|z / L|\right] \\
= & \left(\ln (x-1) /\left(x_{0}-1\right)+2 \tan ^{-1} x\right) \\
& -\left(\ln (x+1) /\left(x_{0}+1\right)+2 \tan ^{-1} x_{0}\right) \\
= & k v / v_{*}
\end{aligned}
$$

where

$$
x=(1+\gamma|z / L|)^{1 / 4} \text {, and } x_{0}=\left(1+\gamma\left|z_{0} / L\right|\right)^{1 / 4}
$$

A full line in Fig. 7 is an assesment of $D^{-1} \cdot S_{1}$ with the observations for $k v / v_{*}$.

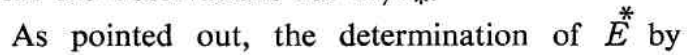
means of the combination of $P$ and $R$ appears to have the gradual transition to free convection

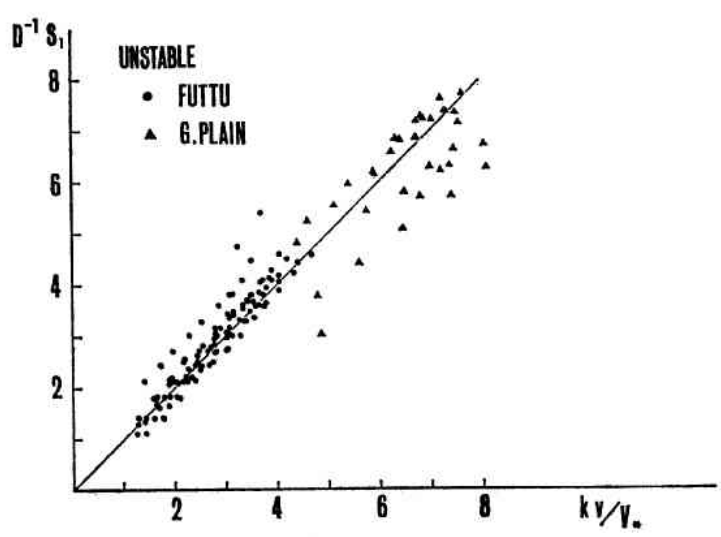

Fig. 7 Universal profile of $k v / v_{*}$ 
from forced convection. The reliability of $P=$ $(1+\gamma|z / L|)^{-1 / 2}$ in the present analysis must subject to test in an independent way. Thus, this is done by means of integral form, which shows the profile of water vapor. Then, the profile of water vapor is given by

$$
\begin{aligned}
D^{-1} & \cdot P_{1}=D^{-1} \cdot(1+\gamma|z / L|)^{-1 / 2} /|z / L| \\
& =\ln \left(x^{2}-1\right) /\left(x_{0}^{2}-1\right)-\ln \left(x^{2}+1\right) /\left(x_{0}^{2}+1\right) \\
& =q-q_{0} / q_{*}
\end{aligned}
$$

where

$$
\begin{aligned}
& q_{*}=\left(-E / k v_{*} \rho_{0}\right)=\text { friction humidity } \\
& x=(1+\gamma|z / L|)^{1 / 4}, \text { and } x_{0}=\left(1+\gamma\left|z_{0} / L\right|\right)^{1 / 4}
\end{aligned}
$$

It is evident from Fig. 8 that $-1 / 2$ power of the shape function for water vapor is consistent well with the observations in unstable condition.

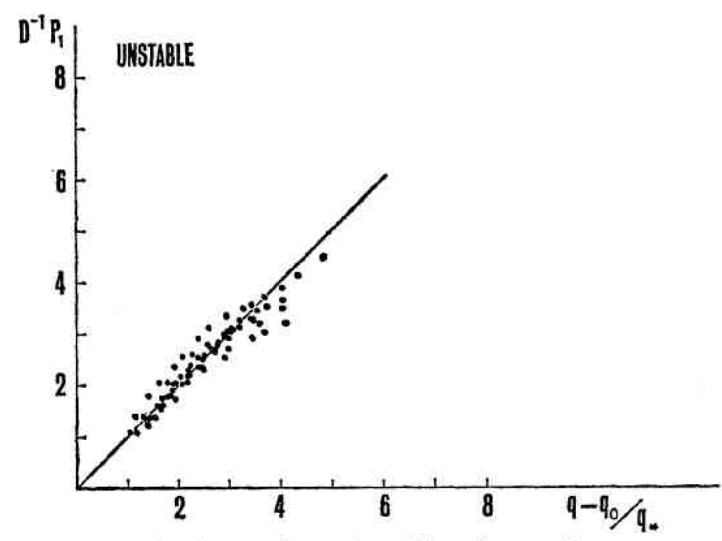

Fig. 8 Universal profile of $q-q_{0} / q_{*}$

Though the formulae for profiles of wind and water vapor are not in familiar expression, the agreement shows to provide reasonable fit to the formula over the range of forced to free convection. This derivations lead to similar equations of Paulson (1967) and Zilitinkevich and Leichtmann (1965).

6. Consistency of the derived-formula with the appropriate parameters

The gradient Richardson number, $R i$ is often defined by

$$
R i=g / \theta_{0} \cdot d \theta / d z(d v / d z)^{2}
$$

Eq. (6-1) can easily rewritten by the aid of the shape functions as

$$
R i=z / L \cdot R / S^{2}
$$

a recent profile formulation by Businger (1966) for the unstable case only suggests

$$
\begin{aligned}
& S=(1-\gamma z / L)^{-1 / 4} \\
& R=(1-\gamma z / L)^{-1 / 2}
\end{aligned}
$$

Although the formulations indicate the dissimilarity of transfer process for sensible heat and momentum, eqs. (6-3) and (6-4) give $z / L=R i$. This, however, has not been accepted with a significant departure (Takeuchi 1961, and Lumley and Panofsky 1964 p.108, 104). Thus, alternative profile form was suggested in $\S 1$. Measured values of $R i$ are shown in Fig. 9.

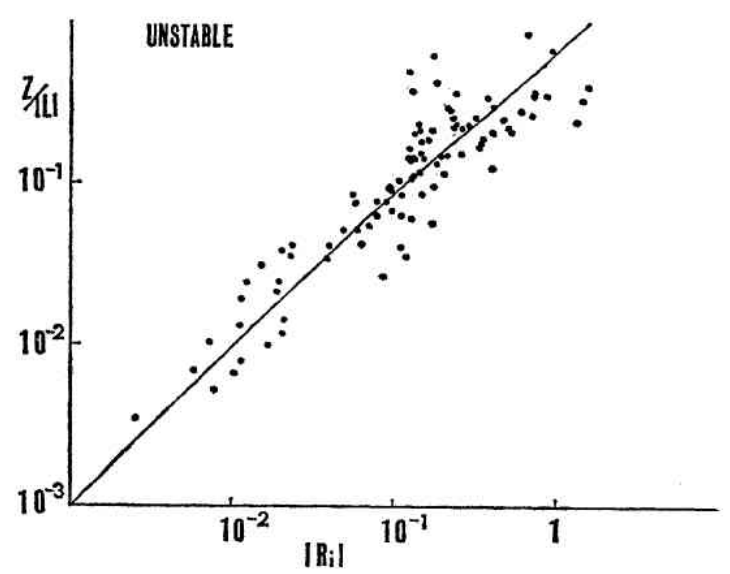

Fig. 9a $R i$ against $|z / L|$. The full line denotes values computed from eq. (6-2) using the shape functions of momentum and of sensible heat in unstable air.

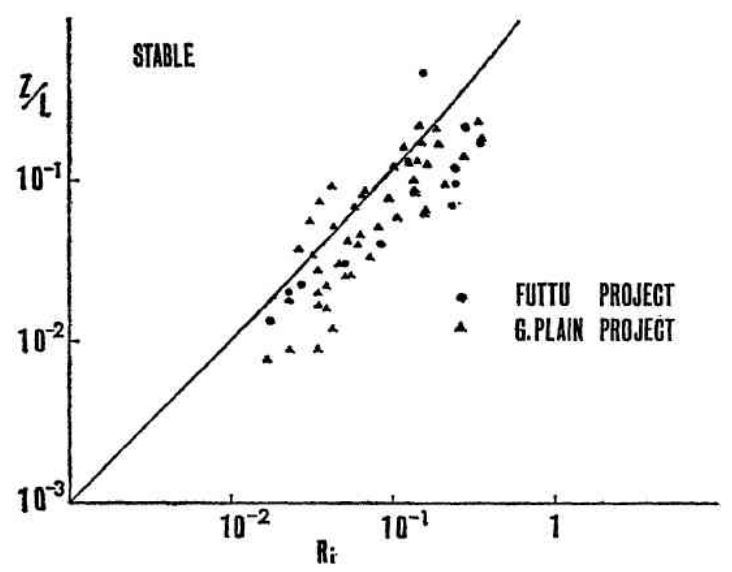

Fig. 9b $R i$ against $z / L$. The full line denotes values computed from eq. (6-2) using the shape functions of momentum and of sensible heat in stable air. 
Full lines in Fig. 9 show the functional relationship. It indicates that the shape functions presented in $\S 1$ are again well consistent with the observations.

\section{Derivation of eddy diffusivity}

Following Lumley and Panofsky (1964), the characteristic lengths in turbulent field are defined respectively by

$$
\begin{aligned}
& v_{*} L_{u}=K_{M} \\
& v_{*} L_{\theta}=K_{H}
\end{aligned}
$$

With the identical consideration, one may also define a length of water vapor transfer as

$$
v_{*} L_{w}=K_{w}
$$

Comparing eq. (7-1) with eqs (2-8)-(2-10), which are definitions of eddy diffusivities for momentum, sen sible heat and water vapor, three lengths are permitted easily to express by means of the shape function respectively by

$$
\begin{aligned}
& L_{u} / k z=1 / S \\
& L_{\theta} / k z=1 / R \\
& L_{w} / k z=1 / P
\end{aligned}
$$

Eq. (7-2) can be rewritten as

$$
\begin{aligned}
& L_{u}=1 / v_{*} \cdot d v / d z \\
& L_{\theta}=1 / k T_{*} \cdot d \theta / d z \\
& L_{w}=1 / k q_{*} \cdot d q / d z
\end{aligned}
$$

Again the non-dimensional lengths are plotted against $z / L$ in Figs $10-1 \sim 10-3$ with observations in unstable and stable air.

In each figure, the full line indicates the results obtained from the shape function. Thus, one can conclude finally that the shape functions are remarkably good agreement with observations that can be obtained.

As has been discussed by Lumley and Panofsky (1964 p. 86-87), the turbulent-length would give roughly the critical wave number at which isotropy could be expected to begin.

It is to be emphasized that eddy diffusivity should be controlled mainly by the turbulentscale in the gross in point of view eq. (7-1). It is also revealed that the heterogeneity of mean flow-field is turned straight to the non-heterogeneity field by action of the distributions of values $d v / d z, d \theta / d z$ and $d q / d z$ in contrast with Karman's assumption for the intutive mixing-

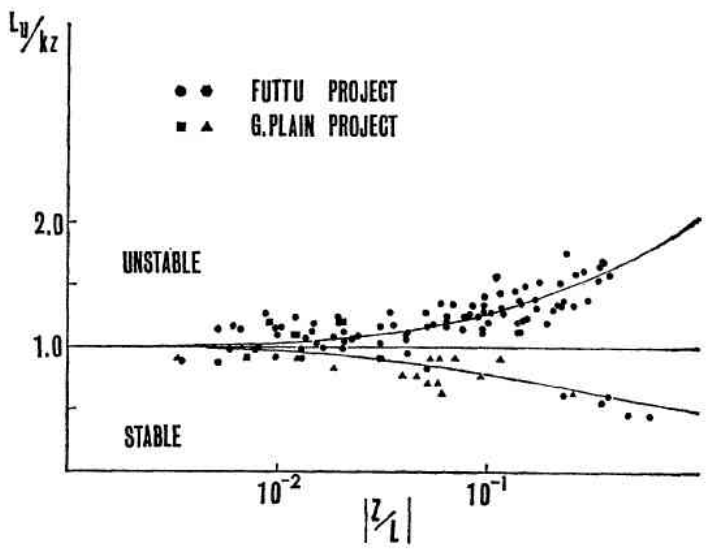

Fig. 10-1 $L_{u}$ against $z / L$. The full lines denote the assesments of $L_{u}$ with the observations in unstable air and in stable nir.

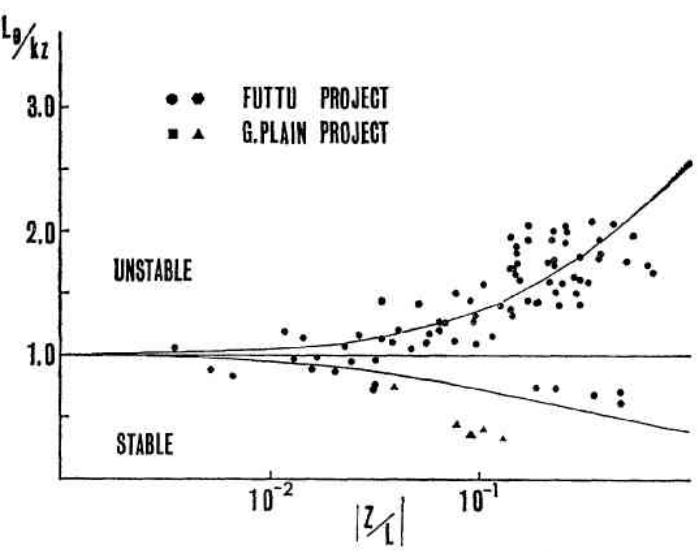

Fig, 10-2 $L_{\theta}$ against $z / L$. The full lines denote the assesments of $L_{\theta}$ with the observations in unstable air and in stable air.

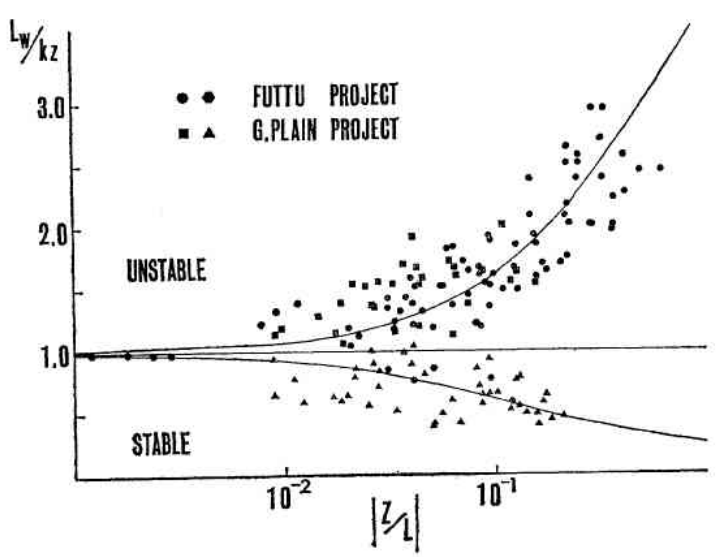

Fig. 10-3 $L_{w}$ against $z / L$. The full lines denote the assesments of $L_{w}$ with the observations in unstable air and in stable air. 
length, which is related moreover to second derivative.

One has noted that there have been paid much attention to obtain a characteristic scale in turbulent-field and the dissipation length with correlation technique or some empirical relationships (Takeuchi and Yokoyama 1963, and Ito 1966). This has not been conclusively proved, however, owing to a lack of good data.

In such circumstances, one may prefer to use the length in the vertical direction presented here in the atmospheric surface layer. As was pointed out by Lumley and Panofsky (1964), the question of relative magnitude of $K_{M}, K_{H}$ and $K_{w}$ has not been satisfactorily resolved. Previous analysis of measurements (Record and Cramer 1966, and Businger 1966) shows that the ratio $K_{H} / K_{M}$ increases with thermal instability. On the other hand, the ratio $K_{H} / K_{M}$ decreases with stable stratification (Lettau and Davidson 1957). These results thus confirm the present analysis excepting $K_{w}$ which seems likely to give a good representation.

\section{Basic consideration of turbulent transfer}

Simplifications including an assumption that the turbulence in the lower layer of the atmosphere is stationary and homogeneous horizontally, leads respectively to the equations for kinetic and thermal energy with non-dimensional form as

$$
\begin{aligned}
& S-z / L-\tilde{\varepsilon}-\widetilde{D}_{M}=0 \\
& R-\widetilde{N}-\widetilde{D}_{H}=0
\end{aligned}
$$

where,

$$
\begin{aligned}
& \tilde{\varepsilon}=\left(k z / v_{*}^{3}\right) \cdot \varepsilon \\
& \bar{D}_{M}=\left(k z / v_{*}^{3}\right) \cdot d / d z \overline{\left(e+p^{\prime} / \rho_{0}\right) w^{\prime}} \\
& \widetilde{N}=\left(z / k v_{*} \cdot T_{*^{2}}\right) \cdot N \\
& D_{H}=\left(z / k v_{*} \cdot T_{*^{2}}{ }^{2}\right) \cdot d / d z\left(1 / 2 \cdot \overline{\theta^{\prime 2} w^{\prime}}\right)
\end{aligned}
$$

$\varepsilon$ : dissipation rate

$e$ : turbulent kinetic energy

$p^{\prime}$ : fluctuation of pressure

$w^{\prime}$ : fluctuation of vertical wind

$\theta^{\prime}$ : fluctuation of temperature

$N$ : rate of adjustment of temperature heterogeneity

Comparing eq. (8-2) with eq. (8-1), corresponded term bears some ressemblance to each other in physical meaning. It is, however, to be noted that eq. (8-1) contains two particular terms which are buoyancy and pressure transport term. One can have moreover an evidence being difference of the resemblance terms. That is to say, the work of Corrison (1951) indicates that the value of $\varepsilon$ differs from that of $N$ as well known. Thus, one should know that no requirement of identity with $S$ and $R$ is feasible from eqs. (8-1) and (8-2).

Now, it is possible that non-dimensional convective energy production is balanced by flux divergence. This leads to a conclusion that the feeding of kinematical energy and local dissipation must be balanced in all thermal stratified flow. The careful observations by Record and Cramer (1966) stand with this correctness. Same statement can be found in Lumley and Panofsky 1964 p. 73-74) except for the range of windless convection, which is not considered in this report, and recent observations of turbulence obtained at the NASA $150 \mathrm{~m}$ meteorological tower also lead that the local mechanical production of turbulent energy is balanced by local viscous dissipation at the $18 \mathrm{~m}$ level (Fichtl 1968).

Making use of discussion mentioned above, one can arrive at a conclusion as

$$
S=\tilde{\varepsilon}=k z / v_{*}^{3} \cdot \hat{s}
$$

or

$$
\varepsilon=v_{*}{ }^{3} / k z \cdot S
$$

From eq. (7-2), one can also show that each length is related as

$$
\begin{aligned}
& L_{u} / L_{\theta}=R / S \\
& L_{u} / L_{w}=P / S \\
& L_{\theta} / L_{w}=P / R
\end{aligned}
$$

and the shape functions can be related each other as

$$
\begin{aligned}
& S^{4}=R^{3} \\
& P=S^{2} \\
& P^{2}=R^{3}
\end{aligned}
$$

To make a problem tractable, it is paid much attention to the relation between eddy diffusivity and turbulent-scale (Richardson 1926, and Heisenberg 1958), and the following relations can be deduced:

$$
\begin{aligned}
& K_{M}=\varepsilon^{1 / 3} \cdot L_{u^{4 / 3}} \\
& K_{H}=\varepsilon^{1 / 3} \cdot L_{u \theta^{4 / 3}} \\
& K_{w}=\varepsilon^{1 / 3} \cdot L_{u w^{4 / 3}}
\end{aligned}
$$


where

$$
L_{u \theta}{ }^{4 / 3}=L_{u}{ }^{1 / 3} \cdot L_{\theta} \text {, and } L_{u w^{4 / 3}}=L_{u}{ }^{1 / 3} \cdot L_{w}
$$

The power of $4 / 3$ in eq. (8-6) is determined to get identical representation, making use of eq. (8-3)-(8-5) with a definition of eddy diffusivity, which is admitted in general to write down by means of non-dimensional form in the atmospheric surface layer as follows:

$$
\begin{aligned}
& K_{M}=k z v_{*} / S \\
& K_{H}=k z v_{*} / R \\
& K_{w}=k z v_{*} / P
\end{aligned}
$$

It is to be emphasized that eq. (8-6) implies an identical meaning completely with eq. (8-7) under conditions of eqs. (8-3), (8-4) and (8-5).

Thus, it is plausible that the mechanism of turbulent transfer for sensible heat is to have interaction between the field of wind and temperature. The same statement makes a suggestion of the self-control between the field of wind and water vapor for the mechanism of turbulet transfer for latent heat.

\section{The governing equation}

As originally developed, the similarity theory (Monin and Obukhov 1954) is related to the vertical distribution of mean wind speed and air temperature.

By considering the governing equation for mean field of velocity and air temperature under the assumptions that are made customarily for the atmospheric surface layer turbulence, a set of averaged equation may then be written by

$$
\begin{aligned}
& K_{M} d v / d z=v_{*}^{2} \\
& g / \theta_{0} \cdot \theta-d / d z\left(\overline{\boldsymbol{p}} / \rho_{0}+\bar{w}^{\prime 2}\right)= \\
& K_{H} d \theta / d z=k v_{*} T_{*}
\end{aligned}
$$

For turbulent energy equation, one can apply eqs (8-1) and (8-2) with good approximation in the atmospheric surface layer.

As can be obtained from eq. (9-2), the vertical gradient of $\left(\overline{\boldsymbol{p}} / \rho_{0}+\bar{w}^{\prime 2}\right)$ would be determined uniquely by the temperature distribution $\theta(z)$. The gradient $d / d z\left(\bar{w}^{\prime 2}\right)$ should depend upon the quantity $d / d z\left(\bar{p} / \rho_{0}\right)$, and if the term can be assumed negligibly small, $\left(\bar{w}^{\prime 2}\right)$ would be expected to be determined from the temperature profile $\theta(z)$. If $\gamma|z / L|$ is considerably larger than unity, the shape function of temperature can be expressed by $R=|(z / L)|^{-1 / 3}$ in unstable air. Then, height dependence of $\bar{w}^{\prime 2}$ makes strong evidence of the observations by Perepelkina (1962). This is only example to exist good evidence.

For the further study, it should be emphasized that great progress could be made through the direct measurement of various fluctuations to make fit for the governing equation including turbulent energy equation.

\section{Concluding remarks}

The foregoing analysis indicated that the transfer-mechanism of momentum and sensible heat were not identical with each other since $S \neq R$, and hence $K_{M} \neq K_{H}$. This findings was consistent with that from the directly measured fluxes by Record and Cramer (1966). And there were also many evidences that the transfermechanism for sensible heat and water vapor were not identical with each other since $R \neq P$, and hence $K_{H} \neq K_{w}$. This finding, however, is no consistent with that obtained from the analysis of shape function by Dyer (1967).

The eddy diffusivities for momentum and sensible heat indicated that the reciprocal of turbulent Prandtl number, $K_{H} / K_{M}$ was larger than unity, and the reciprocal of turbulent Schmidt number $K_{w} / K_{M}$ was larger than $K_{H} / K_{M}$ in the unstable air.

When the differences between $\ddot{E}$ and $\stackrel{*}{H}$ diagrams could be accepted, this would then be strongly supported that eddy diffusivities for sensible heat and water vapor were not identical with each other even in stable air.

An attempt has been made to examine the relation between the turbulent-scale and eddy diffusivity for sensible heat and also for water vapor since this should become to understand well the structure of turbulence. Then, one has showed a conclusion that both temperature-field and wind-field have been responsible for eddy diffusivity of heat. Same circumstance has been approved for eddy diffusivity of water vapor. These will come out to aid of understanding for turbulent transfer in the atmospheric surface layer.

\section{Acknowledgments}

The author wishes to thank Professor G. Yamamoto of Tohoku University for his valuable 
comments. The writter also wishes to express his thanks to the members of the Research Group of Atmospheric Turbulence in Japan, especially Professor G. Sakagami, Drs. E. Inoue, K. Takeuchi and S. Nemoto for their kind advice and discussion. The author wishes to express his sincere thanks to Messrs. $\mathrm{H}$. Uozu and $\mathrm{H}$. Shimura who have helped him in field observations and in preparation of the present work. Finally he wishes to thank Drs. Y. Kodaira, S. Sakuraba and Mr. K. Otani to their encouragement throughout the work.

\section{References}

Businger, J. A., 1961 : On the relation between the spectrum of turbulence and the diabatic wind profile. J. Geophys. Res., 66, 2405-2409.

, 1966: Transfer of momentum and heat in the planetary layer. Proc. Symp. Arctic Heat Budget and Atmospheric Circulation RM-5233NSF, Rand Corp., 305.

1966: Dissimilarity between vertical transfer of momentum and heat in the atmospheric boundary layer. Symposium on Boundary Layers and Tubulence including Geophysical Applications, Abstract.

Corrison, S., 1951: On the spectrum of isotropic temperature fluctuations in an isotropic turbulence. J. Appl. Phys., 22, 469.

Crawford, T.V., 1965: Moisture transfer in free and forced convection. Quart. J. Roy. Meteor. Soc., 91, 18-27.

Dyer, A. J., 1965 : The flux-gradient relation for turbulence heat transfer in the lower atmosphere. Quart. J. Roy. Meteor. Soc., 91, 151-157.

1967: The turbulent transport of heat and water vapor in unstable atmosphere. Quart. J. Roy. Meteor. Soc., 93, 501-508.

Ellison, T.H., 1957: Turbulent transport of heat and momentum from an infinite rough plane. J. Fluid. Mech., 2, 456-466.

Fichtl, G. H., 1968 : Characteristics of turbulence observed at NASA $150 \mathrm{~m}$ meteorological tower. J. Appl. Meteor., 7, 838-844.

Heisenberg, W., 1948: Zur statistischen theorie der turbulenz. Z. Phys., 124, Heft., 7/12, 55.

Ito, S., 1966: Atmospheric diffusion in the earth's boundary layer. Geophys. Magazine, Japan Met. Agency, 33, 1-69.

Kazanski, A.B. and A.S. Monin., 1956: Turbulence in surface inversions. IZV. ANSSSR., Ser. Geofiz. NO. $1,79-86$.

Lettau, H.H. and B. Davidson., 1957: Exploring the atmospheres first mile. Vol. 1, London, New York, Paris, Pergamon Press.
Lumley, J.L. and H.A. Panofsky., 1964: The structure of atmospheric turbulence. John wildy \& Sons., Inc.

Margenau, H. and G.M. Murphy., 1943: The Mathematics of physics and chemistry. D. Van Nostrand Comp. Inc.

McVehil, G.E., 1964: Wind and temperature profiles near the ground in stable stratification. Quart. $J$. Roy. Meteor. Soc., 90, 136-146.

Monin, A.S. and A.M. Obukhov., 1954: The basic laws of turbulence mixing in the surface layer of the atmosphere. Trudy, Geophiz. Inst. ANSSSR. No. 24, 151, 163-187.

Pandolfo, J.P., 1966: Wind and temperature profiles for constant-flux boundary layers in lapse conditions with a variable eddy conductivity to eddy viscosity ratio. J. Atmos. Sci., 23, 495-502.

Paulson, C. A., 1967: Profiles of wind speed, temperature and Humidity over the sea. Sci. Report, NSF. GP-2418, Department of Atmospheric Sciences. Univ. of Washington.

Perepelkina, A.V., 1962: On the characteristics of the turbulence of the layer near the ground. Izvestia, ANSSSR, Geophys. Ser., No. 2, 275.

Priestley, C.H.B., 1954: Convection from a large horizontal surface. Aust. J. Phys., 7, No. 2, 176-201. 1960: A determinant hypothesis for the super adiabatic wind and temperature profiles. Quart. J. Roy. Meteor. Soc., 86, 232-236.

Record, F.A. and H.E. Cramer., 1966: Turbulent energy disspation rates and exchange processes above a non-homogeneous surface. Quart. J. Meteor. Soc. 92, 519-561.

Richardson, L.F., 1926: Atmospheric diffusion shown on a distance-neighbour graph. Proc. Roy. Soc., A 110 , No. 756.

Swinbank, W.C., 1955: An experimental study of eddy transports in the lower atmosphere. C.S.I.R.O. Div. Meteor. Phys. Tech. paper, 2.

Takeuchi, K., 1961: On the structure of the turbulent field in the surface boundary layer. J. Meteor. Soc. Japan 39, 346-367.

and O. Yokoyama., 1963: The scale of turbulence and the wind profile in the surface boundary layer. J. Meteor. Soc. Japan, 41, 108-117.

Taylor, R.J., 1960: Similarity theory in the relation between fluxes and gradients in the lower atmosphere. Quart. J. Roy. Meteor. Soc., 86, 67-78.

Webb, E.K., 1962: Thermal convection with wind shear. Nature, 193, 840-842.

Yamamoto, G., 1959: Theory of turbulent transfer in non-neutral conditions. J. Meteor. Soc. Japan, 37, 60-69.

Zilitinkevich, S. S. and D. L. Leichtman., 1965: Turbulent conditions in the near-surface layer of the atmosphere. IZV., Atmospheric and Oceanic Physics., Vol. 1, No. 2, 150-156. 


\title{
接地気層における乱流輸送の機構
}

\author{
伊藤 昭 三 \\ (気象庁)
}

低層に打ける運動量, 顕熱, 水蒸気量の輸送について微気象の資料の解析結果を示した. 不安定成層では $|z / L|$

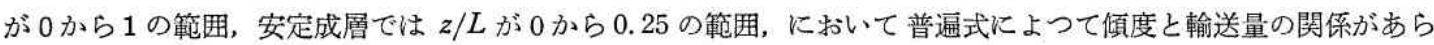
わされる. また接地気層に抢ける風速, 温度, 水蒸気量の分布を検討し, 乱流拆散係数と安定度の関係について議 諭した. さらに乱れのスケールが導かれ, 運動量, 顕熱, 水蒸気についての拡散係数がそれぞれ次の式によつてあ らわされることを示した.

$$
K_{M}=\varepsilon^{1 / 3} L u^{4 / 3} \quad K_{\theta}=\varepsilon^{1 / 3} L_{u^{1 / 3}} \cdot L_{\theta} \quad K_{w}=\varepsilon^{1 / 3} L_{u^{1 / 3}} \cdot L_{w}
$$

ここに $K_{M}, K_{\theta}$ および $K_{w}$ は運動量, 顕熱および水蒸気に対する乱流抎散係数であり， $L_{u}, L_{\theta}, L_{w}$ はそれぞれ 対応する乱れのスケール。・は乱れのエネルギー逸散率である. 